\title{
American Name Society Annual Meeting
}

The annual meeting of the American Name Society will be held December 26, 1994 through January 1, 1995 in tropical San Diego, California. The convention hotel is Le Meridien San Diego, located across the bay and a short 15 -minute ferry ride from downtown San Diego.

Allan Metcalf, Executive Secretary of the American Dialect Society, has arranged for a block of rooms to be set aside, but, he cautions, you might want to reserve early. When making reservations, be sure to mention that you want the American Dialect Society rate, which is $\$ 95$ a day for a king, two doubles, or a studio villa. These rates are available for three days on either side of the meeting dates, so you may want to plan on coming early and staying late. The reservation number is: (619)435-3000. (Le Meridien may have an 800 number, so you might want to call toll-free information before using the number given here.

By the time you read this announcement, the deadline for submitting abstracts for the ANS/MLA sessions will have past, but there is still time to submit an abstract for one of the regular ANS sessions. To do so, send a cover letter with your name and address, along with three copies of a one-page, anonymous abstract on a significant area of onomastics to the program chair:

Edwin D. Lawson

23 Westerly Drive

Fredonia, NY 14063

e-mail: lawson@fredonia.bitnet

fax: 716-673-3397

Deadline for receipt of abstracts is September 1, 1994 